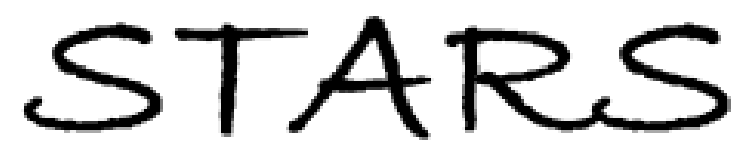

University of Central Florida

STARS

$1-1-1999$

\title{
Role of surface chemistry on the nature of passive oxide film growth on Fe-Cr (low and high) steels at high temperatures
}

\author{
S. Seal \\ University of Central Florida \\ R. Nardelli \\ University of Central Florida
}

A. Kale

University of Central Florida

V. Desai

University of Central Florida

E. Armacanqui

Find similar works at: https://stars.library.ucf.edu/facultybib1990

University of Central Florida Libraries http://library.ucf.edu

This Article; Proceedings Paper is brought to you for free and open access by the Faculty Bibliography at STARS. It has been accepted for inclusion in Faculty Bibliography 1990s by an authorized administrator of STARS. For more information, please contact STARS@ucf.edu.

\section{Recommended Citation}

Seal, S.; Nardelli, R.; Kale, A.; Desai, V.; and Armacanqui, E., "Role of surface chemistry on the nature of passive oxide film growth on Fe-Cr (low and high) steels at high temperatures" (1999). Faculty Bibliography 1990s. 2839.

https://stars.library.ucf.edu/facultybib1990/2839

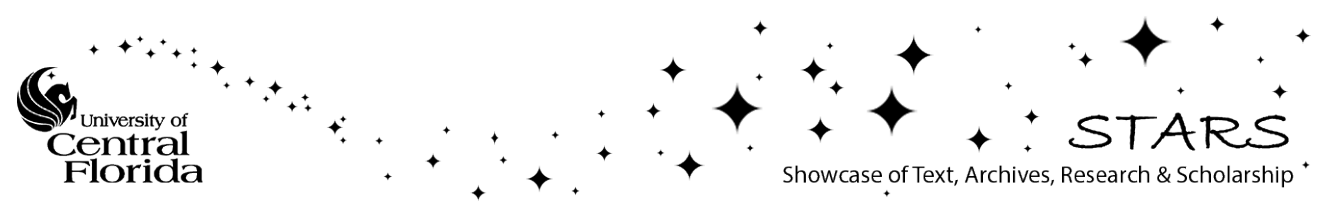




\section{Role of surface chemistry on the nature of passive oxide film growth on $\mathrm{Fe}-\mathrm{Cr}$ (low and high) steels at high temperatures}

S. Seal, R. Nardelli, A. Kale, V. Desai, and E. Armacanqui

Citation: Journal of Vacuum Science \& Technology A 17, 1109 (1999); doi: 10.1116/1.581782

View online: https://doi.org/10.1116/1.581782

View Table of Contents: https://avs.scitation.org/toc/jva/17/4

Published by the American Vacuum Society

\section{ARTICLES YOU MAY BE INTERESTED IN}

Nature of the use of adventitious carbon as a binding energy standard Journal of Vacuum Science \& Technology A 13, 1239 (1995); https://doi.org/10.1116/1.579868

Size dependency variation in lattice parameter and valency states in nanocrystalline cerium oxide Applied Physics Letters 87, 133113 (2005); https://doi.org/10.1063/1.2061873

Formation of chromium oxide on $316 \mathrm{~L}$ austenitic stainless steel Journal of Vacuum Science \& Technology A 14, 2505 (1996); https://doi.org/10.1116/1.580010

X-ray photoelectron spectroscopy valence band data for $\mathrm{ZnS}$, SrS, and $\mathrm{Sr}_{0.45} \mathrm{Ca}_{0.55} \mathrm{Ga}_{2} S_{4}$ luminescent thin films Journal of Vacuum Science \& Technology A 16, 393 (1998); https://doi.org/10.1116/1.581036

Structural and optical characterization of $\mathrm{Cr}_{2} \mathrm{O}_{3}$ nanostructures: Evaluation of its dielectric properties AIP Advances 4, 027121 (2014); https://doi.org/10.1063/1.4867012

Defects and symmetry influence on visible emission of Eu doped nanoceria Applied Physics Letters 92, 123112 (2008); https://doi.org/10.1063/1.2904627

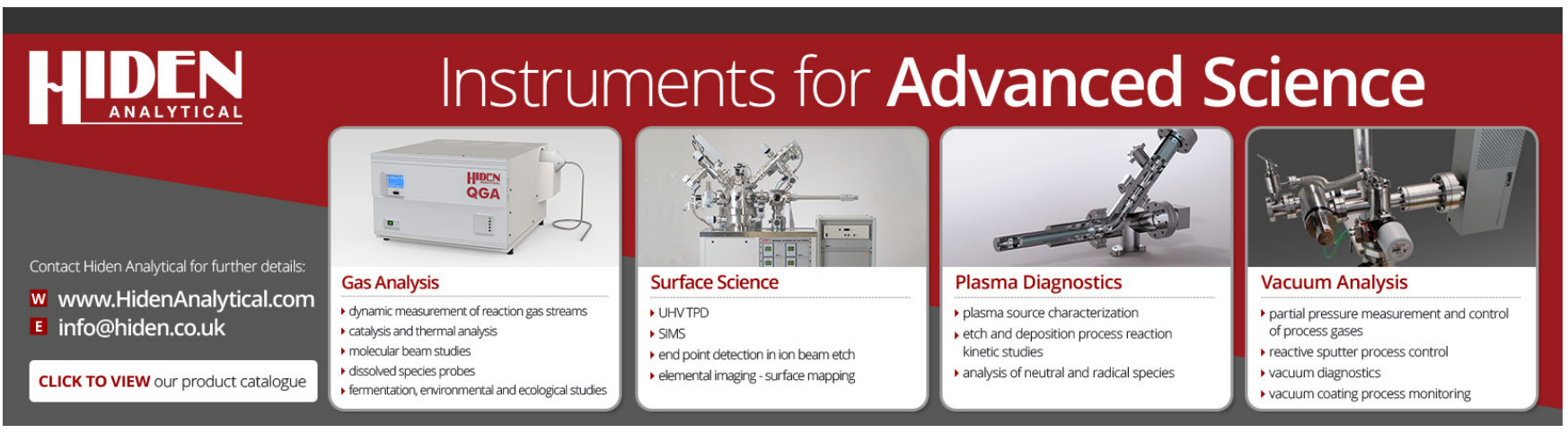




\title{
Role of surface chemistry on the nature of passive oxide film growth on Fe-Cr (low and high) steels at high temperatures
}

\author{
S. Seal, ${ }^{\text {a) }}$ R. Nardelli, ${ }^{\text {b) }}$ A. Kale, and V. Desai \\ Advanced Materials Processing Analysis Center (AMPAC), Mechanical, Materials \& Aerospace \\ Engineering (MMAE), University of Central Florida, Orlando, Florida 32816 \\ E. Armacanqui \\ Rayovac Corporation, Madison, Wisconsin
}

(Received 2 November 1998; accepted 22 February 1999)

\begin{abstract}
High temperature materials degradation or protection of $\mathrm{Fe}-\mathrm{Cr}$ alloys are often related to the nature of their oxide scale formation. Breakdown of passive oxide films lead to localized corrosion. Various alloying elements are often incorporated in these alloys to prevent high temperature oxidation. The addition of selected alloying elements is cumbersome and not always cost effective. In this article, we investigate the role of rare earth oxide coatings on high temperature corrosion prevention of both low and high $\mathrm{Cr}$ steel. An in situ high temperature oxidation setup has been built to study the oxidation kinetics of both coated and uncoated low and high $\mathrm{Cr}$ steels under ambient pressure and dry air. Reduction in scale growth kinetics is observed in the presence of coating. While scanning electron microscopy and x-ray diffraction are employed to study the structure and morphology of the oxide films, x-ray photoelectron spectroscopy and Auger electron spectroscopy are used to study the surface chemistry of the oxide layer. This article relates some of these data to explain the nature of scale growth kinetics (linear or logarithmic or parabolic) observed in both low and high Cr steels. (C) 1999 American Vacuum Society. [S0734-2101(99)11304-6]
\end{abstract}

\section{INTRODUCTION}

The effect of addition of rare earth elements such as $\mathrm{Y}$, $\mathrm{Ce}, \mathrm{Sc}$, La, etc., in their oxide form to both $\mathrm{Cr}_{2} \mathrm{O}_{3}$ and $\mathrm{Al}_{2} \mathrm{O}_{3}$ forming alloys for improving their high temperature oxidation behavior has been reviewed in a great detail. ${ }^{1-4}$ Several mechanisms have been proposed to explain the beneficial effects of rare earth additions to high temperature alloys. ${ }^{5-9}$ However any conclusive single mechanism is yet to evolve to explain such effects, i.e., reduction in scale growth kinetics.

The high temperature material degradation or protection shown by $\mathrm{Fe}-\mathrm{Cr}$ alloys are often related to the nature of their oxide scale formation. Breakdown of passive oxide films often lead to localized corrosion. The surface oxides and hydroxides are of wide importance and can exist in varying oxidation states. In order to understand the high temperature oxidation and corrosion of $\mathrm{Fe}-\mathrm{Cr}$ alloys, the surface chemistry of the oxides needs to be examined in detail. A particular interest to us is to extend the use of x-ray photoelectron spectroscopy [(XPS) or often known as ESCA] to distinguish between various oxides formed in both coated and uncoated steel during oxidation. This investigation presents the results on the isothermal oxidation behavior for $\mathrm{Fe}-\mathrm{Cr}$ alloys (low and high $\mathrm{Cr}$ ) in dry air with and without superficially coated $\mathrm{CeO}_{2}$ coatings. While x-ray diffraction (XRD) and scanning electron microscopy (SEM) investigates the structure and scale morphology, XPS provides detailed surface chemical studies of both coated and uncoated $\mathrm{Fe}-\mathrm{Cr}$ alloys at elevated temperature. Moreover, the application of the cerium oxide

\footnotetext{
${ }^{a)}$ Electronic mail: sseal@ pegasus.cc.ucf.edu

${ }^{b)}$ Also at: Naval Nuclear Power Training Command, Orlando, FL 32813.
}

coatings is considered to be the most practical procedure for ensuring high local concentration of the active element within the scale and thus preventing the material degradation and failure.

\section{EXPERIMENT}

\section{A. Materials used}

The spectrographic analysis of the low and high $\mathrm{Cr}$ steel samples used in this study is listed in Table I. Cerium oxide powder and reagent grade ethyl alcohol were purchased from Aldrich Chemicals, USA.

\section{B. Sample preparation}

All the steel samples were mechanically rough polished using $600 \mathrm{SiC}$ grit paper followed by cleaning in methanol. Some specimens were coated with cerium oxide from a slurry of $\mathrm{CeO}_{2}$ powder dispersed in ethyl alcohol. The calculated coating thickness was in the range of $2-5 \mu \mathrm{m}$.

\section{Arrangement for oxidation studies}

The oxidation method and the details of the oxidation setup were the same as reported elsewhere. ${ }^{6}$ An electronic microbalance (Sartorious MP8: accuracy of $\pm 0.1 \mathrm{mg}$ ) attached to a computer was used to record the continuous mass change for various time-temperature programs. Experiments were carried out at $923 \mathrm{~K}$ in dry air for $24 \mathrm{~h}$ to examine the improvement if any with regard to scale adherence and suppression in scale growth rate in the presence of rare earth oxide coatings. 
TABLE I. Typical spectrographic analysis composition of low and high $\mathrm{Cr}$ steels.

\begin{tabular}{lllcccccccccr}
\hline \hline Steel \% & $\mathrm{C}$ & $\mathrm{Mn}$ & $\mathrm{P}$ & $\mathrm{S}$ & $\mathrm{Si}$ & $\mathrm{Cu}$ & $\mathrm{Ni}$ & $\mathrm{Cr}$ & $\mathrm{Mo}$ & $\mathrm{Al}$ & $\mathrm{N}$ & $\mathrm{Fe}$ \\
\hline Low $\mathrm{Cr}$ & 0.08 & 0.6 & 0.015 & 0.03 & 0.02 & 0.06 & 0.04 & 0.06 & 0.05 & 0.1 & & rest \\
High Cr & 0.025 & 1 & 0.04 & 0.03 & 1 & & 0.6 & $17-20$ & $1.75-2.25$ & & 0.03 & rest \\
\hline \hline
\end{tabular}

\section{Oxide scale characterization}

At the termination of each oxidation run, each sample with its oxide layer was examined visually, optically, and by SEM attached with an energy dispersive spectroscopy (EDS) to access the scale composition, morphology, and the nature of various oxide phases formed on the steel substrate.

Oxide surface chemical analysis was performed using a 5400 PHI ESCA (XPS) spectrometer having a base pressure of $10^{-10}$ Torr using Al $K \alpha X$ radiation $(1486 \mathrm{eV}$, line width $0.7 \mathrm{eV}$ ) with a power of $350 \mathrm{~W}$. Survey and individual highresolution spectra were recorded with a pass energy of 44 and $17 \mathrm{eV}$ to achieve the maximum instrument resolution. Data were collected with at least 1 (in survey mode) and 0.1 eV/step (in high-resolution mode) to be sure to identify the subtle features in the XPS spectrum. The spectrometer scale was calibrated using gold $\left(4 f_{7 / 2}\right)=84 \pm 0.2 \mathrm{eV}$. The charging shifts produced by the insulating oxide samples were removed by using a binding energy scale by fixing the $\mathrm{C}(1 s)$ binding energy of the hydrocarbon part of the adventitious carbon line at $284.6 \mathrm{eV} .{ }^{10}$ Nonlinear backgrounds were removed from the spectra using a method described by Sherwood. ${ }^{11}$ XPS data were smoothed to remove incidental noise spikes using a Savitsky and Golay smoothing program. This program allowed us to deconvolute peaks by specifying the peak's position, height, width, and shape. Nonlinear least square curve fitting was performed using a Gaussian/ Lorentzian peak shape, ${ }^{11,12}$ which include $x$-radiation satellites in the fitting routine. The shape parameters include the peak's Gaussian/Lorentzian ratio and tail characteristics such as height, slope, and exponential to linear tail mix. In addition spectra were analyzed using an automated incremental peak deconvolution program which varied the peak height within an envelope over a complete range to determine the best fit, checked by using the $\chi$-squared value to the smoothed data.

Sputter depth profiling was carried out using a PHI 600 scanning Auger microprobe by sputtering an area of $5 \mathrm{~mm}^{2}$ of the oxide films by high purity (99.999\%) argon ions and simultaneously analyzing a small part of the area by scanning auger multiprobe. The following ion gun parameters were used during etching: ion beam energy $3 \mathrm{keV}$, emission current $25 \mathrm{~mA}$.

\section{RESULTS AND DISCUSSION}

\section{A. Kinetics}

The oxidation kinetic plots for both ceria coated and uncoated low and high $\mathrm{Cr}$ steel at $923 \mathrm{~K}$ under isothermal exposure are presented in Fig. 1. Coated samples in the case of high $\mathrm{Cr}$ steel showed marked reduction in the rate of scale growth as compared to the low $\mathrm{Cr}$ coated steel. The lack of $\mathrm{Cr}$ in the latter sample seems to allow the oxidation to continue at a significant rate. It is the reduction in the rate due to coating that is of interest in the low $\mathrm{Cr}$ steel. It is observed that the high $\mathrm{Cr}$ coated steel after $24 \mathrm{~h}$ of exposure registered 20 times less mass gain than that of the uncoated one. In both cases the kinetics of the oxide scale growth follows a logarithmic behavior and not the parabolic law. These kinetic results seemed to be valid at this temperature. ${ }^{13}$ Such improved performance in the coated high $\mathrm{Cr}$ steel is attributed to enhanced $\mathrm{Cr}$ diffusion through a distorted lattice as well as through grain boundaries to the alloy surface, thus facilitating an early establishment of protective external $\mathrm{Fe}$ doped $\mathrm{Cr}_{2} \mathrm{O}_{3}$ or a Cr-rich spinel layer. This is reported in the section of XPS results later.

\section{B. SEM and XRD}

Figure 2 represents the selected top-surface SEM morphology of the oxide scales formed on uncoated and $\mathrm{CeO}_{2}$ coated high and low $\mathrm{Cr}$ steels. The uncoated sample clearly demonstrates both cracks and oxide spallation [Fig. 2(a)]. The EDS analysis (not shown) on the top scale surface shows mainly iron oxides in low $\mathrm{Cr}$ steel and $\mathrm{Cr}_{2} \mathrm{O}_{3}, \mathrm{Fe}_{2} \mathrm{O}_{3}$ (Cr, Fe, and $\mathrm{O}$ peaks) in high $\mathrm{Cr}$ steel. Figure 2(b) shows a uniform coating on the high $\mathrm{Cr}$ steel surface with cerium oxide particles whose presence is further confirmed from the EDS results. The amount of $\mathrm{Cr}$ and $\mathrm{Si}$ is suppressed. $\mathrm{Si}$ is believed to be taking part in the internal oxidation, ${ }^{6}$ (also found to form silica from XPS studies) as well as surface

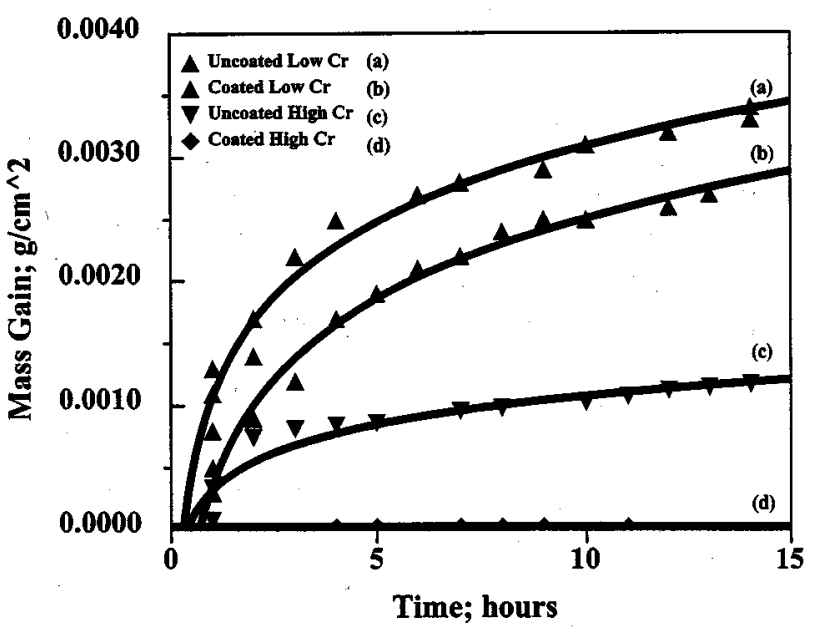

FIG. 1. Mass gain/unit area vs time for uncoated and $\mathrm{CeO}_{2}$ coated low and high $\mathrm{Cr}$ steel during isothermal oxidation at $923 \mathrm{~K}$. 


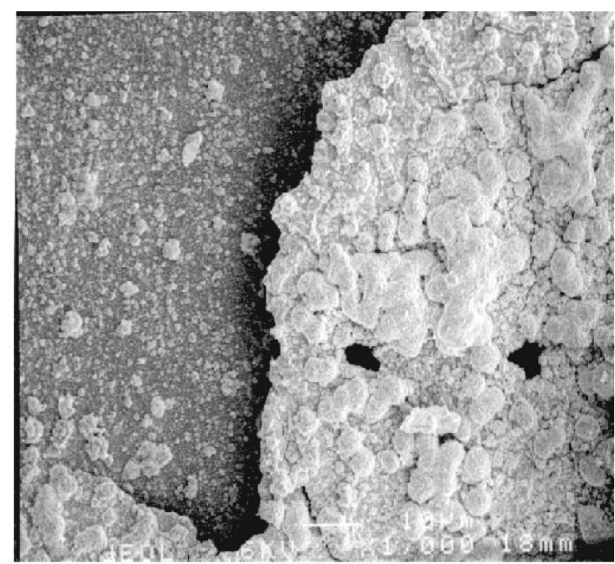

(a)

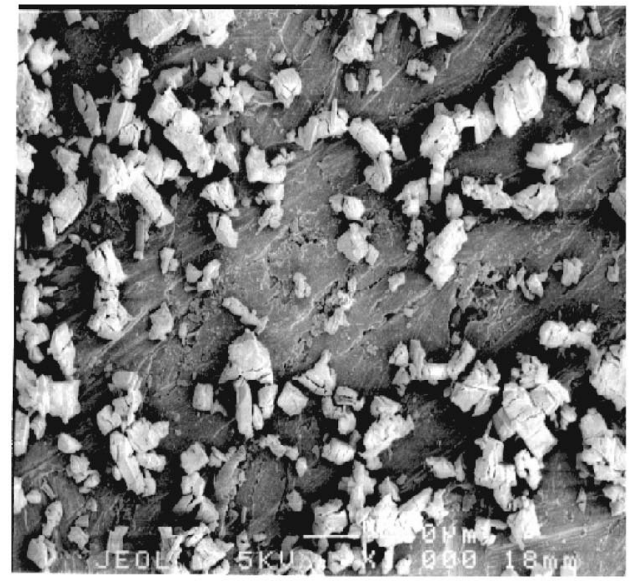

(b)

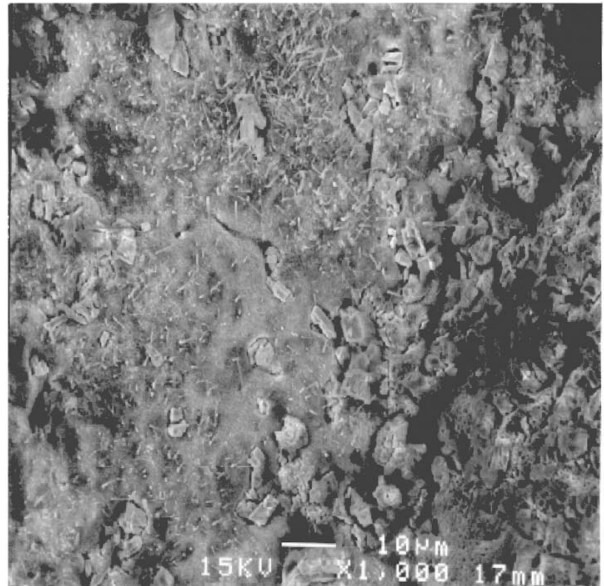

(c)

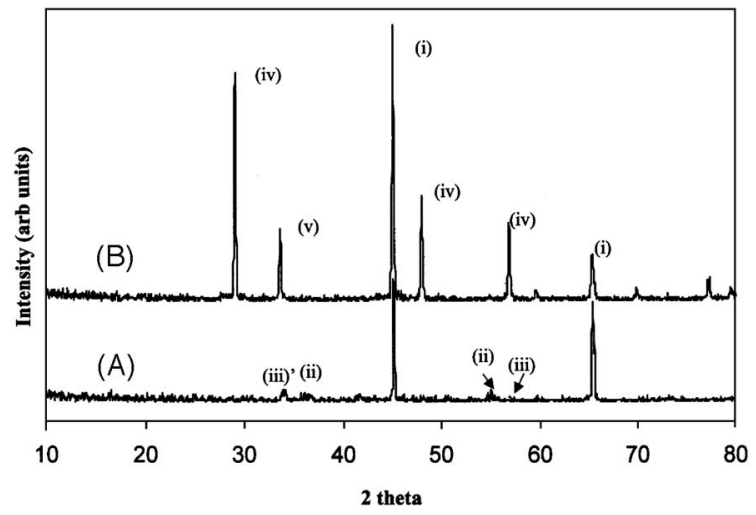

(d)

FIG. 2. SEM micrographs (SEI) of the top scale surface formed on: (a) uncoated high $\mathrm{Cr}$ steel, (b) $\mathrm{CeO}_{2}$ coated high $\mathrm{Cr}$ steel, and (c) $\mathrm{CeO}{ }_{2}$ low $\mathrm{Cr}$ steel. $\mathrm{XRD}$ spectra for high $\mathrm{Cr}$ steel (A) uncoated oxidized and (B) coated-oxidized peak identification: (i) $\mathrm{Fe}-\mathrm{Cr},(\mathrm{ii}) \mathrm{Cr}_{2} \mathrm{O}_{3}$, (iii) $\mathrm{Fe}_{2} \mathrm{O}_{3}$, (iii)' $\mathrm{FeCr}_{2} \mathrm{O}_{4}$, (iv) $\mathrm{CeO}_{2}$, (v) $\mathrm{CeO}_{2} \cdot \mathrm{Cr}_{2} \mathrm{O}_{3}$.

oxide formation. Similar results were found in the coated low $\mathrm{Cr}$ steel [uniform coating with some scale spallations: Fig. 2(c)], except that there was no $\mathrm{Cr}$ and the $\mathrm{Fe}$ signal is suppressed due to the presence of cerium oxide. The reduction in scale growth kinetics is very much dependent on the $\mathrm{Cr}$ content of the steel which is responsible for the formation of the protective $\mathrm{Cr}_{2} \mathrm{O}_{3}$ layer.

XRD analysis of the oxide scales on bare low $\mathrm{Cr}$ steel indicates the presence of $\mathrm{Fe}_{2} \mathrm{O}_{3}$. The $\mathrm{Fe}_{2} \mathrm{O}_{3}$ peaks in coated steel are suppressed drastically by $\mathrm{CeO}_{2}$ peaks (in coated steel), thus indicating the formation of barrier that can suppress the corrosion to a certain extent. Some mixed $\mathrm{FeO} . \mathrm{Fe}_{2} \mathrm{O}_{3}$ peaks are also detected. A typical XRD pattern [Fig. 2(d)] of the top scales formed on bare and coated high $\mathrm{Cr}$ oxidized steel showed the formation of the following compounds: $\mathrm{Fe}_{2} \mathrm{O}_{3}, \mathrm{Cr}_{2} \mathrm{O}_{3}$, and possibly $\mathrm{FeCr}_{2} \mathrm{O}_{4}$ in uncoated steel and $\mathrm{CeO}_{2} \cdot \mathrm{Cr}_{2} \mathrm{O}_{3}$ with $\mathrm{CeO}_{2}$ in coated steel sample. The main $\mathrm{Fe}-\mathrm{Cr}(001)$ peak is further depressed in the coated sample with no $\mathrm{Ce}_{2} \mathrm{O}_{3}$ present, which was later confirmed by XPS. The formation of $\mathrm{Ce}_{2} \mathrm{O}_{3}$ (more thermodynamically stable) needs much higher temperature and is reported in the study of $\mathrm{Fe}-20 \% \mathrm{Cr}$ alloy with $\mathrm{Ce}$ additions. ${ }^{14}$ The presence of cerium oxide suppresses the scale growth and prevents material degradation.

\section{XPS results}

\section{XPS survey spectra}

The surface chemistry and (\%) atomic concentration of the oxide layer are studied using $\mathrm{x}$-ray photoelectron spectroscopy (XPS). Figures 3 and 4 represent the XPS survey spectra of bare and coated low and high $\mathrm{Cr}$ steel under selected oxidizing conditions. Table II lists the atomic surface concentration of selected steels. In Fig. 3(b), the oxidized low $\mathrm{Cr}$ steel shows an increase in surface $\mathrm{Fe}$ and $\mathrm{O}$ concentration indicating the migration of cations to the surface. In this case, the band gap is reduced to $1.5 \mathrm{eV}$ as compared to $2.2 \mathrm{eV}$ in the uncoated sample showing the presence of transition metal species on the surface. The coated oxidized steel [Fig. 3(c)] shows a marked decrease in Fe (i.e., reduction in outward cation migration) and $\mathrm{O}$ concentration and the surface is mostly coated with $\mathrm{CeO}_{2}$. An increase in the band gap 


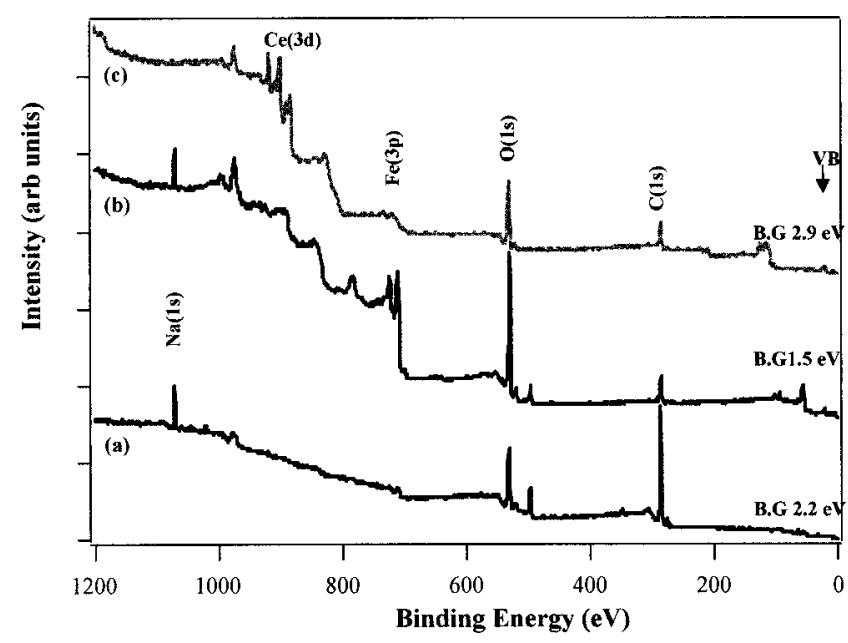

FIG. 3. XPS 0-1200 eV survey spectra for (a) low $\mathrm{Cr}$ steel, (b) low $\mathrm{Cr}$ steel-oxidized (c) low $\mathrm{Cr}$ steel coated and oxidized.

to $2.9 \mathrm{eV}$ indicates the insulating nature of the oxide scale. Corresponding XPS $\mathrm{Fe}(2 p)$ and $\mathrm{O}(1 s)$ spectra (not shown) of the bare low $\mathrm{Cr}$ steel sample reveal the presence of $\mathrm{Fe}^{+2}$ (B.E. $709.6 \mathrm{eV}$ ), $\mathrm{Fe}^{+3}$ (B.E. $710.9 \mathrm{eV}$ ), and physisorbed $\mathrm{OH}$ species $[\mathrm{O}(1 S)$ B.E. $531.9 \mathrm{eV}]$ on the surface due to low temperature oxidation (LTO). ${ }^{15}$

The survey spectra of bare, oxidized, and coated high $\mathrm{Cr}$ steel, [Figs. 4(a)-4(c)] indicate the definitive presence of carbonaceous species [Fig. 4(a)] along with surface hydroxides (from $\mathrm{Cr}, \mathrm{O}$, and $\mathrm{Fe}$ high resolution XPS spectra) in the bare alloy. The relative $\mathrm{Cr} / \mathrm{Fe}$ ratio increases from 0.94 (bare) to 3.5 during oxidation, an indication of $\mathrm{Cr}$ cation migration, and it decreases to 2.5 in the coated oxidized steel. This indicates the early passivation of the steel surface due to ceria-based rare earth oxide coating. The relative $\mathrm{Cr} / \mathrm{O}$ ratio is 0.09 in coated-oxidized steel with respect to 0.026 in the uncoated-oxidized steel, indicating a change in the relative presence of $\mathrm{Cr}$ cations versus $\mathrm{O}$ anions. Thus in the presence of a coating, the formation of an early chromia layer might have changed the oxidation from outward cation migration to inward anion ingress and thereby decreasing the oxidation rate as observed from the oxidation kinetics data. This effect is well documented in the case of 316 and 321 steels as reported in the literature. ${ }^{4-7}$

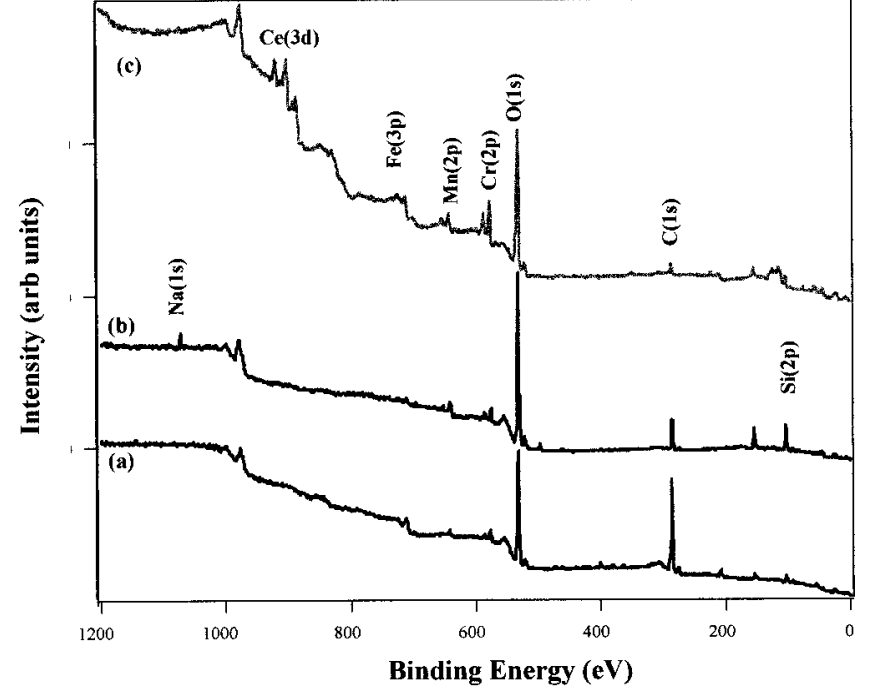

FIG. 4. XPS 0-1200 eV survey spectra for (a) high $\mathrm{Cr}$ steel, (b) high $\mathrm{Cr}$ steel-oxidized (c) high $\mathrm{Cr}$ steel coated and oxidized.

\section{XPS $\operatorname{Cr}(2 p)$ for high $\mathrm{Cr}$ steel}

The relative $\mathrm{Cr}$ content in steel plays an important role in $\mathrm{Cr}_{2} \mathrm{O}_{3}$ oxide formation in high temperature material degradation. In the case of low $\mathrm{Cr}$ steel, $\mathrm{Cr}$ content is very low to be detected by XPS and this Cr did not play any significant role in the surface protective chromia formation. Thus this article is focused on the $\mathrm{Cr}$ chemistry of the high $\mathrm{Cr}$ steel. Figures $5(\mathrm{a})-5(\mathrm{c})$ represents the $\operatorname{Cr}\left(2 p_{3 / 2}\right)$ XPS spectrum for bare, oxidized, and coated oxidized steel at $923 \mathrm{~K}$ for $24 \mathrm{~h}$. The bare steel [Fig. 5(a)] shows a main peak at $576.2 \mathrm{eV}$ along with two small shoulder peaks at 574.3 and $578.0 \mathrm{eV}$, representing the presence of $\mathrm{Cr}_{2} \mathrm{O}_{3}, \mathrm{Cr}^{0}$, and $\mathrm{Cr}$-hydroxide type species, respectively. ${ }^{16}$ The surface oxide and hydroxide formation is due to the natural passivation (LTO) and physisorbed $\mathrm{OH}$ from air exposure. ${ }^{15}$ The full-width at halfmaximum (FWHM) of $\mathrm{Cr}\left(2 p_{3 / 2}\right)$ in Figs. 5(b) and 5(c) increases to 2.7 and $3 \mathrm{eV}$ as compared to the $\mathrm{Cr}(2 p)$ line in the bare sample, indicating the presence of multiple $\mathrm{Cr}$ containing oxide species due to high temperature exposure. The decrease in $\mathrm{Cr}(2 p)$ B.E. $(575.5 \pm 0.2 \mathrm{eV})$ in $\mathrm{Cr}_{2} \mathrm{O}_{3}$ is due to formation of possible $\mathrm{Cr}-\mathrm{Fe}-\mathrm{Mn}$ transition metal mixed oxides (also revealed from XRD analysis). A further decrease in $\mathrm{Cr}(2 p)$ B.E. to $577.4 \mathrm{eV}$ in Fig. 5(c) is due to the

TABLE II. Surface atomic concentration of key elements calculated from XPS survey spectrum.

\begin{tabular}{lccccccc}
\hline \hline & $\mathrm{Cr}$ & $\mathrm{Fe}$ & $\mathrm{Mn}$ & $\mathrm{Si}$ & $\mathrm{O}$ & $\mathrm{Ce}$ & $\mathrm{C}$ \\
\hline High Cr steel & 1.2 & 1.6 & 0.43 & 5.1 & 31.3 & & 63 \\
Bare & 1.4 & 0.4 & 1.3 & 17 & 54.2 & & 23 \\
Oxidized & 5.6 & 2.6 & 2.2 & 12.6 & 60.0 & 1.8 & 15 \\
Ceria coated-oxidized & & & & & & & \\
Low Cr steel & & 0.8 & & & 16 & & 77 \\
Bare & & 10 & & 58 & & 24 \\
Oxidized & 3.0 & & & 45 & 4.0 & 45 \\
Ceria coated-oxidized & & & & &
\end{tabular}



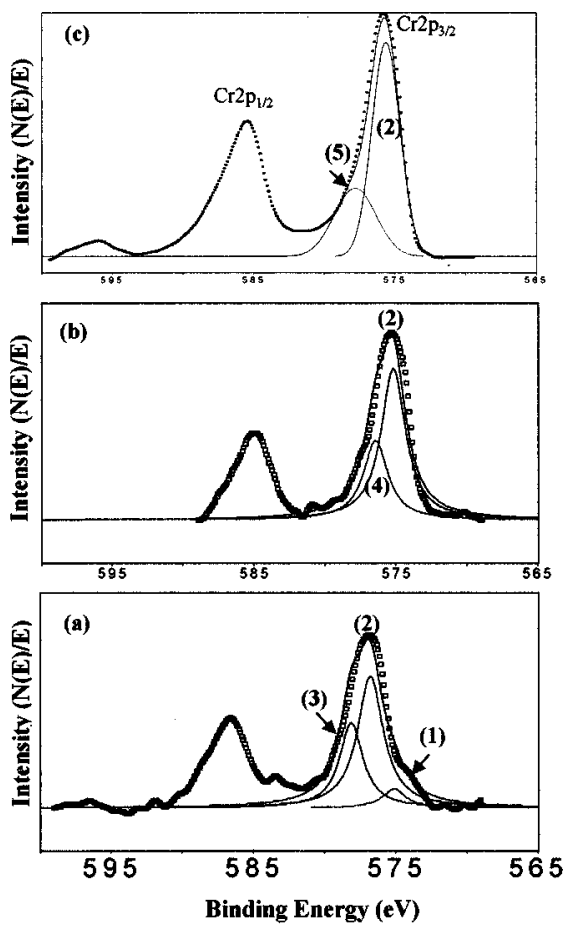

FIG. 5. XPS $\operatorname{Cr}(2 p)$ spectra for (a) high Cr steel, (b) high $\mathrm{Cr}$ steel-oxidized (c) oxidized ceria coated high $\mathrm{Cr}$ steel. Experimental core level spectra $(\cdots)$, and the result of computer fitted spectra (-). Suggested peak identification: (1) $\mathrm{Cr}^{0}$, (2) $\mathrm{Cr}_{2} \mathrm{O}_{3}$, (3) $\mathrm{Cr}-\mathrm{OH}$ (4) $\mathrm{Fe}-\mathrm{Mn}-$ Chromates, (5) $\mathrm{Cr}-$ $\mathrm{Ce}-\mathrm{O}$ type

possible formation of $\mathrm{Cr}-\mathrm{Ce}-\mathrm{O}$ type oxides. Insertion of a more ionic $\mathrm{Ce}-\mathrm{O}$ type bond in the $\mathrm{Cr}-\mathrm{O}$ lattice makes the $\mathrm{Cr}-\mathrm{O}$ bond more covalent. A similar type of compound has been observed in the $\mathrm{CeO}_{2}$ coated chromia. ${ }^{17}$ Formation of

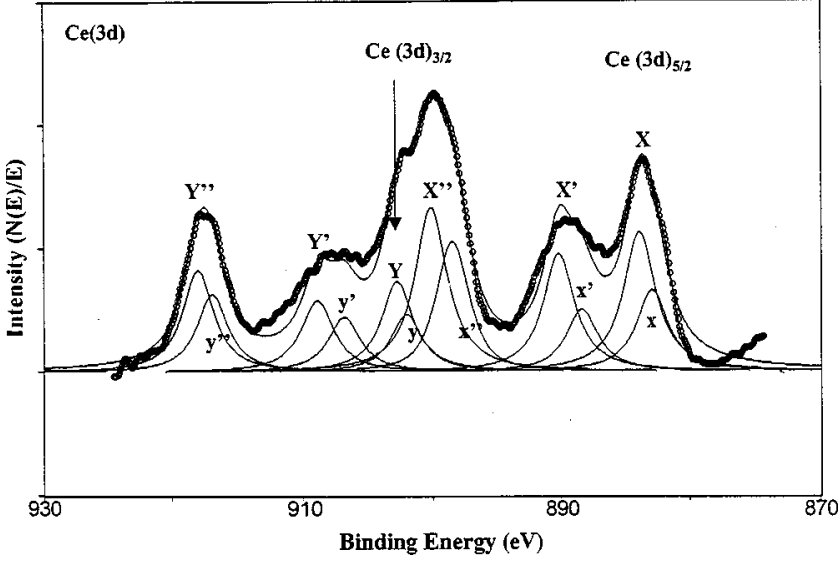

FIG. 6. XPS Ce( $3 d)$ spectrum for high $\mathrm{Cr}$ steel coated and oxidized. Experimental core level spectra $(\cdots)$, and the result of computer fitted spectra (一). Suggested peak identification: [see the text and Table III(a)].

chromia in the presence of ceria is responsible for preventing the material degradation and is consistent with the suppression in oxide growth kinetics (Fig. 1).

\section{Cerium surface chemistry}

Table III lists the $\mathrm{Ce}(3 d)$ binding energy values of both high and low $\mathrm{Cr}$ (samples 1 and 2) coated oxidized steel. Figure 6 shows a typical $\mathrm{Ce}(3 d)$ XPS spectra of ceria coated high $\mathrm{Cr}$ oxidized steel. The twelve peaks consists of main $\mathrm{Ce}$ core level lines and it's associated satellites for both $\mathrm{CeO}_{2}$ and $\mathrm{Ce}_{1+x} \mathrm{O}_{2-x}$. The ratio between the core and the satellite lines (derived from the control $\mathrm{CeO}_{2}$ sample and also present in the existing literature ${ }^{18}$ ) is maintained during the peak fitting. The complex multipeaked $\mathrm{Ce}(3 d)$ spectra are due to the hybridization of $\mathrm{Ce}(4 f)$ with ligand orbitals and frac-

TABLE III. (a) XPS binding energies (accuracy $\pm 0.2 \mathrm{eV}$ ) of $\mathrm{Ce}(3 d)$ for $\mathrm{CeO}_{2}$ oxidized coated low and high $\mathrm{Cr}$ steel. (b) Auger depth profile analysis for $\mathrm{CeO}_{2}$ coated oxidized high $\mathrm{Cr}$ steel.

\begin{tabular}{|c|c|c|c|c|c|c|}
\hline $\begin{array}{l}\text { (a) } \\
\text { B.E. }(\mathrm{eV})\end{array}$ & \multicolumn{3}{|c|}{$\begin{array}{c}\mathrm{CeO}_{2} \text { coated and oxidized high } \mathrm{Cr} \text { steel (1) } \\
\text { Ce } 3 d_{5 / 2}\end{array}$} & \multicolumn{3}{|c|}{$\mathrm{Ce} 3 d_{3 / 2}$} \\
\hline $\begin{array}{l}\text { B.E. }(\mathrm{eV}) \\
\text { B.E. }(\mathrm{eV}) \\
\pm 0.2 \mathrm{eV}\end{array}$ & $\begin{array}{l}883.7(X) \\
883.0(x)\end{array}$ & $\begin{array}{c}889.8\left(X^{\prime}\right) \\
889.3\left(x^{\prime}\right) \\
\Delta_{X^{\prime}-X} 6.1\end{array}$ & $\begin{array}{l}900.1\left(X^{\prime \prime}\right) \\
899.2\left(x^{\prime \prime}\right) \\
\Delta_{X^{\prime \prime}-X} 16.4\end{array}$ & $\begin{array}{l}902.63(Y) \\
901.6(y) \\
\Delta_{Y-X} 18.9\end{array}$ & $\begin{array}{l}908.8\left(Y^{\prime}\right) \\
907.5\left(y^{\prime}\right) \\
\Delta_{Y^{\prime}-Y} 6.17\end{array}$ & $\begin{array}{c}918\left(Y^{\prime \prime}\right) \\
917\left(y^{\prime \prime}\right) \\
\Delta_{Y^{\prime \prime}-Y} 15.4\end{array}$ \\
\hline $\pm 0.2 \mathrm{eV}$ & $\mathrm{CeO}_{2}$ coate & $\begin{array}{l}\text { idized low } \\
\qquad \text { Ce } 3 d_{5 / 2}\end{array}$ & eel (2) & & Ce $3 d_{3 / 2}$ & \\
\hline $\begin{array}{l}\text { B.E. }(\mathrm{eV}) \\
\pm 0.1 \mathrm{eV}\end{array}$ & $883(x)$ & $\begin{array}{c}889.3\left(x^{\prime}\right) \\
\Delta_{x^{\prime}-x} 6.2\end{array}$ & $\begin{array}{l}899.2\left(x^{\prime \prime}\right) \\
\Delta_{x^{\prime \prime}-x} 16.2\end{array}$ & $\begin{array}{l}901.5(y) \\
\Delta_{y-x} 18.5\end{array}$ & $\begin{array}{r}907.5\left(y^{\prime}\right) \\
\Delta_{y^{\prime}-y} 6.0\end{array}$ & $\begin{array}{l}918.5\left(y^{\prime \prime}\right) \\
\Delta_{y^{\prime \prime}-y} 17.0\end{array}$ \\
\hline
\end{tabular}

(b)

Sputtering
Beneath the coating
4 min
$8 \mathrm{~min}$

$10 \mathrm{~min}$
Top surface mostly $\mathrm{Ce}$ and $\mathrm{O}$

\begin{tabular}{ccccc}
\hline $\mathrm{Si}$ & $\mathrm{C}$ & $\mathrm{O}$ & $\mathrm{Cr}$ & $\mathrm{Fe}$ \\
35.5 & 11.1 & 19.7 & 18.0 & 15.5 \\
18.0 & 5.00 & 46.0 & 19.0 & 12.0 \\
6.00 & $\cdots$ & 60.8 & 22.6 & 10.2 \\
$\cdots$ & $\cdots$ & 66.5 & 24.0 & 9.4 \\
\hline
\end{tabular}

Note: $x^{\prime}, x^{\prime \prime}, y, y^{\prime \prime}$ and $X^{\prime}, X^{\prime \prime}, Y, Y^{\prime \prime}$ are satellite lines of Ce $(3 d)$. 
tional occupancy of the valence $4 f$ orbitals. ${ }^{19-21}$ The $\mathrm{CeO}_{2}$ XPS spectrum reveals the nature of passivation of steel underneath the cerium oxide coating. The $\mathrm{Ce}\left(3 d_{5 / 2}\right)$ and $\mathrm{Ce}\left(3 d_{3 / 2}\right)$ lines for both steels showed a spin orbit splitting of $18.7 \pm 0.2 \mathrm{eV}$ (for example, see Fig. 6 for high $\mathrm{Cr}$ steel) and is consistent with the literature data for $\mathrm{CeO}_{2} \cdot{ }^{16,18}$ Both low and high $\mathrm{Cr}$ coated oxidized steels do not show formation of any $\mathrm{Ce}_{2} \mathrm{O}_{3}$ type compounds (also evident from earlier XRD data), instead the later shows both $\mathrm{CeO}_{2}(883.0 \mathrm{eV})$ and $\mathrm{Ce}_{1+x} \mathrm{O}_{2-x}(883.7 \mathrm{eV})$ species on the surface. A particular $3 d_{3 / 2}$ multielectron satellite at $918 \mathrm{eV}$ is present in both the samples indicating the presence of $\mathrm{Ce}(+4)$ species only and not $\mathrm{Ce}(+3)$, although the presence of $\mathrm{Ce}(+3)$ formation is being suggested in the literature. ${ }^{17}$

The $\mathrm{Ce}(3 d)$ spectrum contains mainly $3 d_{5 / 2}$ features at binding energies 883.0, 883.7(X), 889.8( $\left.X^{\prime}\right)$, 900.1( $\left(X^{\prime \prime}\right)$ and $883.0(x), 889.3\left(x^{\prime}\right), 899.2\left(x^{\prime \prime}\right)$ for both high and low $\mathrm{Cr}$ coated and oxidized steel, respectively. The similar $3 d_{3 / 2}$ features for both the coated steels appeared to be at 902.63(Y), 908.8( $\left.Y^{\prime}\right), 918\left(Y^{\prime \prime}\right)$ and 901.6(y), 907.5( $\left.y^{\prime}\right)$, $918.5\left(y^{\prime \prime}\right) \mathrm{eV}$, respectively. The peaks at 883.7 and $889.8 \mathrm{eV}$ have generally been assigned for final states with strong mixing of $4 f^{1}$ and $4 f^{2}$ configuration. These states arise from the core hole potential in the final state and the $4 f$ hybridization in the initial state. ${ }^{19-21}$

The low $\mathrm{Cr}$ steel shows the presence of $\mathrm{CeO}_{2}$ on the surface and the reduction in the scale growth is not as prominent as in high $\mathrm{Cr}$ coated steel (see kinetics data in Fig. 1). The high $\mathrm{Cr}$ steel in the presence of ceria coating showed the presence of both $\mathrm{CeO}_{2}$ and $\mathrm{Ce}_{1+x} \mathrm{O}_{2-x}$ phases at binding energies 883.0 and $883.7 \mathrm{eV}$, respectively. The increase in the binding energy of the latter is attributed to the excess charge transfer from cerium to oxygen. The presence of oxygen deficient cerium oxide layer allows the inward ingress of oxygen and enhances early formation of $\mathrm{Cr}_{2} \mathrm{O}_{3}$ scales and thus prevents high temperature oxidation and is consistent with kinetics plot (Fig. 1), where the mass gain is 20 times less in the coated high $\mathrm{Cr}$ steel. The increase in the $\mathrm{Ce}(3 d)$ binding energies as compared to the existing literature ${ }^{18}$ is due to the fact that in the presence of transition metal oxides, $\mathrm{Ce}$ in $\mathrm{CeO}_{2}$ is more ionic, i.e., high B.E. and thus the former experiences a decrease in their binding energies.

Relative movement of anions and cations during the oxidation process are further investigated using Auger electron spectroscopy. Auger depth profile analysis [data shown in Table III(b)] has revealed the top surface layer to be composed of $\mathrm{CeO}_{2}$ and a small presence of $\mathrm{Cr}$ oxides (along with other oxides). With sputtering, an increase in oxygen content towards the oxide-metal interface indicates the change in the oxidation mechanism from outward cation migration to inward anion ingress. A relative increase in $\mathrm{Cr}$ content reveals an early $\mathrm{Cr}_{2} \mathrm{O}_{3}$ layer formation at the scale/metal interface, thus preventing high temperature degradation.

\section{Valence band studies}

A detailed understanding of the surface chemistry associated with oxidation and prevention is needed to tackle more
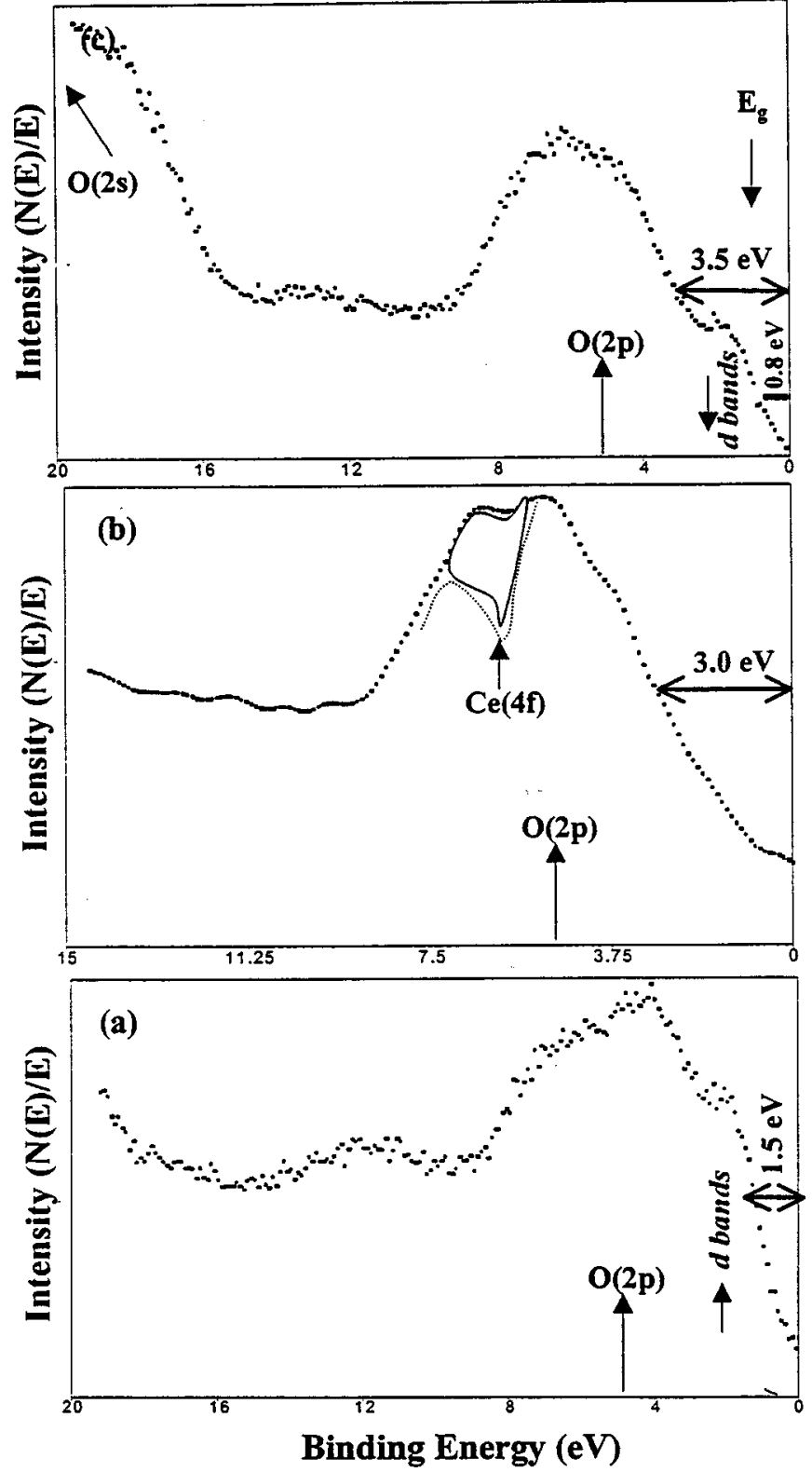

FIG. 7. XPS valence band spectra: (a) low $\mathrm{Cr}$ steel oxidized, (b) low $\mathrm{Cr}$ steel- $\mathrm{CeO}_{2}$ coated and oxidized, (c) high $\mathrm{Cr}$ steel- $\mathrm{CeO}_{2}$ coated and oxidized.

complex problems associated with corrosion. XPS displays valuable core level chemical shifts, which allows one to identify various chemical species on the corroded surface, but there often remain difficulties in distinguishing subtle chemical differences. A number of studies on application of valence band photoemission in oxidation and corrosion are reported in the literature. ${ }^{22-24}$ This article presents the valence band spectra of oxidized and coated low $\mathrm{Cr}$ steels [Figs. 7(a) and 7(b)] and high Cr coated steel [Fig. 7(c)]. Figure 7(a) shows the valence band region of oxidized low $\mathrm{Cr}$ steel, where the broad hump between 4 and $8 \mathrm{eV}$ represents the hybridization of $\mathrm{O}(2 s)$ and $\mathrm{Fe}(3 d)$ density of states with a band gap of $1.5 \mathrm{eV}$, indicating the outward cation migration, also seen from both XPS survey and XRD data. The band gap increases to $3 \mathrm{eV}$ in Fig. 7(b) indicating 
the presence of $\mathrm{CeO}_{2}$ and the region between 4 and $7 \mathrm{eV}$ indicates the interaction of $\mathrm{Ce}(4 f)$ and $\mathrm{O}(2 s)$ shells (broad feature) in the valence shell. Hardly any transition metal oxides $\left(\mathrm{Fe}_{2} \mathrm{O}_{3}\right)$ are observed thus indicating the suppression of cation migration. Figure 7(c) shows the valence band region of ceria coated high $\mathrm{Cr}$ steel. The cerium oxide presence is prominent, and the presence of small transition metal oxides is also evident from the peaks at $0.5-2.3 \mathrm{eV}$. This is consistent with the core level XPS data. In particular, it is sufficient to note that the part of the transition metal oxide metal band structures dominated by $\mathrm{O}(2 p)$ remains relatively fixed (at 5-6 eV below $E_{F}$, the pseudo Fermi energy) for a series of third period $3 d$ oxides. ${ }^{15}$ One should also note that the valence band region gives information from a greater depth than the core region due to significantly greater kinetic energies (thus escape depths) of the photoelectrons involved. The relative amount of oxide to metal is very high in the valence band region than in the core region due to greater depth probed by this region.

So it is postulated from the XPS, AES, XRD, and SEM results that at the beginning of the exposure of the steel to high temperature, a ceria modified chromia oxide film is favored by outward $\mathrm{Cr}^{+3}$ diffusion. In the transition stage, growth of $\mathrm{Cr}_{2} \mathrm{O}_{3}$ layer occurs above and beneath the ceria modified layer by outward $\mathrm{Cr}^{+3}$ diffusion and inward $\mathrm{O}^{-2}$ ingress through the initially formed defect oxide lattice as evident from the XPS results. Table III(b) shows the auger depth profile analysis for $\mathrm{CeO}_{2}$ coated oxidized high $\mathrm{Cr}$ steel. At longer oxidation times, anion transport becomes dominant and the surface shows less oxygen [see Table III(b)] and increases with depth (i.e., inward $\mathrm{O}^{-2}$ ingress is favored in presence of ceria coating). Similar phenomenon studied by SEM, EDS, and x-ray mapping is sited in the case of 316, 321 , and 304 steels. ${ }^{6,7}$ Postoxidation (and also Auger) analysis reveals the presence of cerium oxide particles at the scale/ air interface [Table III(b)] and acted not only as heterogeneous nucleation sites at the alloy surface but also as sources of active element ionic segregation to block faster diffusion paths such as grain boundaries within the scale. ${ }^{6}$ In the case of low $\mathrm{Cr}$ steel, the presence of $\mathrm{CeO}_{2}$ prevents the scale growth to lesser extent by suppressing the formation of iron oxides. Cr concentration is very small to be detected by the XPS. Thus a critical $\mathrm{Cr}$ content is required to observe the beneficial effects of rare earth oxide coatings in high temperature degradation of steels.

\section{CONCLUSIONS}

The presence of superficially applied rare earth oxide $\mathrm{CeO}_{2}$ coating has shown improvement in high temperature oxidation behavior of $\mathrm{Fe}-\mathrm{Cr}$ alloys. Although the presence of $\mathrm{Ce}$ alone has improved the oxidation behavior of both low and high $\mathrm{Cr}$ steels, the best improvement was achieved with the high $\mathrm{Cr}$ steels. In the presence of $\mathrm{Ce}$, the oxidation rate has been reduced by a factor of 20 in the latter case. Without the coating, the surface layer of the steel is shown to be a mixture of principally $\mathrm{Cr}_{2} \mathrm{O}_{3}$ and $\mathrm{Fe}_{2} \mathrm{O}_{3}$ and in cases $\mathrm{Mn}$ in form of $\mathrm{MnO}_{2}$. The application of $\mathrm{Ce}$ on the surface acts as a reactive ionic element, which facilitates the formation of an early $\mathrm{Cr}_{2} \mathrm{O}_{3}$ protective layer. Thus, the ion migration has shifted from outward cation migration to inward anion ingress (from Auger analysis). The presence of Ce suppresses the formation of $\mathrm{Fe}_{2} \mathrm{O}_{3}$ allowing the $\mathrm{Cr}_{2} \mathrm{O}_{3}$ layer to form uninhibitedly and uniformly. The XPS data also seem to indicate that the presence of $\mathrm{Ce}$ allows transition metal oxides to be more covalent and thus protective. These covalent structures are speculated to have a polymer type nature, which improves the oxide layer's ability for slower oxygen uptake to provide a more protective barrier.

\section{ACKNOWLEDGMENTS}

This publication is based on the work sponsored by University of Central Florida Research Initiation Grant (68-01902), Office of Sponsored Research. The authors also acknowledge the use of UCF-CIRENT Materials Characterization Facility.

${ }^{1}$ D. P. Moon and M. J. Bennett, Mater. Sci. Forum 43, 263 (1989). ${ }^{2}$ P. Papaiacovou, R. J. Hussey, D. F. Mitchell, and M. J. Graham, Oxid. Met. 33, 19 (1990).

${ }^{3}$ D. P. Whittle and J. Stringer, Philos. Trans. R. Soc. London, Ser. A 295 , 309 (1980).

${ }^{4}$ S. K. Mitra, S. K. Roy, and S. K. Bose, Oxid. Met. 34, 101 (1990).

${ }^{5}$ S. K. Roy, S. Seal, S. K. Bose, and M. Caillet, J. Mater. Sci. Lett. 12, 249 (1993).

${ }^{6}$ S. Seal, S. K. Bose, and S. K. Roy, Oxid. Met. 41, 139 (1994).

${ }^{7}$ S. C. Kuiry, S. Seal, S. K. Bose, and S. K. Roy, ISIJ Int. 34, 599 (1994).

${ }^{8}$ C. G. Giggins, B. Kear, F. S. Pettit, and J. K. Tien, Met. Trans. 5, 1685 (1975).

${ }^{9}$ W. W. Smeltzer, Oxid. Met. 23, 251 (1985).

${ }^{10}$ T. L. Barr and S. Seal, J. Vac. Sci. Technol. A 13, 1239 (1995).

${ }^{11}$ P. M. A. Sherwood, in Practical Surface Analysis by Auger and Photoelectron Spectroscopy, edited by D. Briggs and M. P. Seah (Wiley, London, 1983), p. 445.

${ }^{12}$ P. M. A. Sherwood, in Data Analysis in XPS and AES in Practical Electron Spectroscopy, edited by D. Briggs and M. P. Seah (Wiley, New York, 1990), Appendix 3, p. 555.

${ }^{13}$ D. A. Jones, Corrosion, 2nd ed. (Prentice Hall, New York, 1996), p. 429.

${ }^{14}$ T. N. Rhys-Jones, H. J. Grabke, and P. Schmidt, in High Temperature Alloys; Their Exploitable Potential, edited by J. B. Mariott, M. Merz, J. Nihoul, and J. Ward (Elsevier, London, 1987), p. 97.

${ }^{15}$ T. L. Barr, Modern ESCA (Chemical Rubber, Boca Raton, 1994).

${ }^{16}$ D. Wagner, W. M. Riggs, L. E. Davis, J. F. Molder, and G. E. Muilenberg, Handbook of XPS (Perkin Elmer, Eden Prairie, MN, 1979).

${ }^{17}$ S. Roure, F. Czerwinski, and A. Petric, Oxid. Met. 42, 75 (1994).

${ }^{18}$ T. L. Barr, in Quantitative Surface Analysis of Materials, edited by N. S. McIntyre (American Society for Testing and Materials, 1978), Vol. 643, p. 83.

${ }^{19}$ A. Fujimori, Phys. Rev. B 28, 2282 (1938).

${ }^{20}$ E. Wuilloud, B. Delley, W. Schinieder, and Y. Baer, Phys. Rev. Lett. 53, 2519 (1984).

${ }^{21}$ J. Jo and A. Kotari, Phys. Scr. 35, 570 (1987).

${ }^{22}$ P. M. A. Sherwood, J. Vac. Sci. Technol. A 9, 1493 (1991).

${ }^{23}$ S. Thomas, P. M. A. Sherwood, N. Singh, A. Al-Sharif, and M. J. O'Shea, Phys. Rev. B 39, 6640 (1989).

${ }^{24}$ P. M. A. Sherwood, Phys. Rev. B 41, 10151 (1990). 